\title{
Effect of electronic medication reconciliation at the time of hospital discharge on inappropriate medication use in the community: an interrupted time-series analysis
}

\author{
Blayne Welk MD MSc, Lauren Killin MSc, Jennifer N. Reid MSc, Kelly K. Anderson PhD, \\ Salimah Z. Shariff PhD, Andrew Appleton MD, Glen Kearns HBA MRE, Amit X. Garg MD PhD
}

Abstract

Background: It is unclear if enhanced electronic medication reconciliation systems can reduce inappropriate medication use and improve patient care. We evaluated trends in potentially inappropriate medication use after hospital discharge before and after adoption of an electronic medication reconciliation system.

Methods: We conducted an interrupted time-series analysis in 3 tertiary care hospitals in London, Ontario, using linked health care data (2011-2019). We included patients aged 66 years and older who were discharged from hospital. Starting between Apr. 13 and May 21, 2014, physicians were required to complete an electronic medication reconciliation module for each discharged patient. As a process outcome, we evaluated the proportion of patients who continued to receive a benzodiazepine, antipsychotic or gastric acid suppressant as an outpatient when these medications were first started during the hospital stay. The clinical outcome was a return to hospital within 90 days of discharge with a fall or fracture among patients who received a new benzodiazepine or antipsychotic during their hospital stay. We used segmented linear regression for the analysis.

Results: We identified 15932 patients with a total of 18405 hospital discharge episodes. Before the implementation of the electronic medication reconciliation system, $16.3 \%$ of patients received a prescription for a benzodiazepine, antipsychotic or gastric acid suppressant after their hospital stay. After implementation, there was a significant and immediate $7.0 \%$ absolute decline in this proportion (95\% confidence interval $[\mathrm{Cl}] 4.5 \%$ to $9.5 \%$ ). Before implementation, $4.1 \%$ of discharged patients who newly received a benzodiazepine or antipsychotic returned to hospital with a fracture or fall within 90 days. After implementation, there was a significant and immediate $2.3 \%$ absolute decline in this outcome (95\% Cl $0.3 \%$ to $4.3 \%)$.

Interpretation: Implementation of an electronic medication reconciliation system in 3 tertiary care hospitals reduced potentially inappropriate medication use and associated adverse events when patients transitioned back to the community. Enhanced electronic medication reconciliation systems may allow other hospitals to improve patient safety.

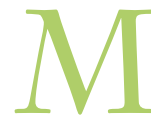
edication reconciliation is the process of ensuring a patient's medication record is updated with the most appropriate information. This is important during transitions of care to prevent unintended errors that can lead to patient harm. Several systematic reviews have shown that medication reconciliation reduces medication discrepancies, which may reduce adverse patient outcomes, hospital readmissions, emergency department visits and excess health care costs..$^{1-3}$ For example, medications that were intended for use only while a patient was admitted to hospital can cause harm if they are inadvertently prescribed to the patient for use after hospital discharge. ${ }^{4}$ Medication reconciliation is a required operational practice by Accreditation Canada, and Health Quality Ontario identified it as a priority indicator of safe and efficient clinical care. ${ }^{5}$
Initially, medication reconciliation was performed using a pen-and-paper process. However, the introduction of hospital-based electronic medical record (EMR) systems has led to the creation of enhanced electronic medication reconciliation systems that interact directly with the patient's hospital medication records. Canadian health care providers have invested billions of dollars in hospital-based EMRs with the intention of improving hospital efficiency and

Competing interests: None declared.

This article has been peer reviewed.

Correspondence to: Blayne Welk, bkwelk@gmail.com CMAJ Open 2021 November 30. DOI:10.9778/cmajo.20210071 
patient outcomes. ${ }^{6}$ However, the effect of the different components of commercial EMR systems, such as medication reconciliation systems, on patient care is unclear. ${ }^{7}$ Previous studies have reported conflicting results of whether electronic medication reconciliation systems can reduce medication discrepancies, and little evidence has shown that they improve clinically relevant outcomes. ${ }^{8,9}$

In 2014, regional hospitals in London, Ontario, upgraded their EMR and added an enhanced electronic medication reconciliation system. Our objective was to evaluate the trends in potential inappropriate medication use after hospital discharge before and after adoption of this medication reconciliation system. We evaluated both a process outcome (i.e., the proportion of patients aged 66 years and older who received a benzodiazepine, antipsychotic or gastric acid suppressant as an outpatient, ${ }^{4,10}$ when these medications were first started during the hospital stay) and a clinical outcome (i.e., the proportion of patients who returned to hospital with a fall or fracture among those who received a new benzodiazepine or antipsychotic during their hospital stay). We hypothesized that there would be less continued outpatient use of these medications, and fewer falls and fractures after implementation of the enhanced electronic medication reconciliation system.

\section{Methods}

\section{Study design and setting}

All residents of Ontario have access to a single, universal health care system. We conducted a retrospective, interrupted time-series analysis of routinely collected health data from Jan. 1, 2011, to Mar. 26, 2019, from the 3 hospitals in London, Ont., St. Joseph's Health Care London, and the University and Victoria Hospital campuses of London Health Sciences Centre. These hospitals are large academic centres and, in total, have about 2000 inpatient beds for acute and chronic care. They provide tertiary care to a catchment area of almost 2 million people. We report study findings using the recommended guideline for observational studies that use routinely collected health data. ${ }^{11}$

\section{Data sources}

The 3 London hospitals use an EMR from Cerner, a supplier of widely used EMR solutions. We used unique encoded identifiers to link data from the hospitals' Cerner EMR to 12 health care databases held at ICES, including the Canadian Institute for Health Information's Discharge Abstract Database and Same Day Surgery Database, the Ontario Health Insurance Plan Database, the National Ambulatory Care Reporting System Database, the Registered Persons Database and the Ontario Drug Benefit Database. These data sets were analyzed at ICES. Additional information on the databases and their validity is provided in Appendix 1, Section 1, available at www.cmajopen.ca/content/9/4/E1105/suppl/DC1.

We used these data sources to measure patient characteristics, prescription drug use, covariate information and outcome data. Variable definitions and the relevant administrative codes are in Appendix 1, Section 2.

\section{Enhanced electronic medication reconciliation system}

The hospitals upgraded the existing Cerner EMR on Apr. 13, 2014 (University Hospital), Apr. 27, 2014 (Victoria Hospital), and May 21, 2014 (St. Joseph's Hospital). This upgrade was implemented across each of the hospitals in a single day on the specified dates, after which physicians used the new electronic medication reconciliation system, in the Cerner EMR.

This system replaced a long-standing paper-based process. The paper-based process required the physician or pharmacist to copy medications manually from the medication administration record to a carbon-copy form and use tick boxes to indicate changes. The new electronic system required physicians to complete a computerized discharge module and explicitly indicate whether patients should continue each medication that was ordered during their hospital stay.

\section{Identification of hospitalization discharge episodes}

Using the EMR data from each hospital, we identified all patients aged 66 years and older (i.e., eligible for governmentfunded outpatient medication coverage) who were discharged to home or long-term care during the study period. We divided discharge episodes from our consecutive 98-month study time period into 2-month intervals. Intervals 1-19 represented the period before use of the enhanced electronic medication reconciliation system (Feb. 1, 2011, to Mar. 31, 2014), and intervals 20-49 represented the period with its use (Apr. 1, 2015, to Mar. 26, 2019).

We included only hospital discharge episodes in which the patient was newly dispensed a medication of interest (i.e., a benzodiazepine, antipsychotic or gastric acid suppressant) during their hospital stay. We excluded discharge episodes where the patient had inaccurate data characteristics, died during their hospitalization or within 5 days of discharge, had a length of stay of zero days, had an admission to a hospital in the previous 6 months (to reduce carryover effects from the previous admission) or were readmitted to hospital or returned to an emergency department within 5 days of discharge (as they may not have had an opportunity to fill discharge prescriptions). We also excluded discharge episodes if the patient had a diagnosis from a hospital admission in the previous 6 months that suggested the medications of interest would be appropriate to continue as an outpatient (e.g., we excluded patients with a diagnosis of gastrointestinal bleed, as the use of a proton pump inhibitor after discharge would likely be appropriate). For a full list of these conditions and coding algorithms, see Appendix 1, Section 3.

To maximize data quality, we retained only records for which the admission and discharge dates recorded in Cerner matched those in the Discharge Abstract Database. The unit of analysis was a hospital discharge; patients could therefore be included multiple times if they were rehospitalized more than 6 months after their last hospitalization. 


\section{Outcomes}

We defined 3 classes of medications a priori as potentially inappropriate, namely benzodiazepines, antipsychotics and gastric acid suppressants. Benzodiazepines are sedatives that are commonly used to treat temporary hospital-based sleep disturbances, but can lead to cognitive impairment, sedation, falls, and dependence or addiction. ${ }^{12}$ Antipsychotics are often used off-label for agitation and hospitalinduced delirium. Long-term use is associated with anticholinergic effects, tardive dyskinesia, falls, arrhythmias and cognitive decline. ${ }^{13}$ Gastric acid suppressants are often prescribed for general, hospital-based gastrointestinal symptoms. Long-term use is associated with an increased risk of pneumonia, infection by Clostridium difficile, fracture risk (with use for more than a year), hypomagnesemia and serious drug interactions. ${ }^{14,15}$ Individual medications are listed in Appendix 1, Section 4. We selected these medications because of their frequency of use in hospitalized, older adult patients, ${ }^{4}$ their inclusion in the Beers Criteria of potentially inappropriate medications for older adults ${ }^{10}$ and their potential for clinically important, adverse drug reactions.

The primary process outcome was the proportion of people who filled a prescription for 1 of these medications in the outpatient setting within 5 days of hospital discharge when these medications were first started during the hospital stay. Patients could be prescribed more than 1 of these medication classes.

The primary clinical outcome was a hospital visit for a fall or fracture within 90 days of hospital discharge among the subgroup of patients who received a benzodiazepine or an antipsychotic in hospital. Falls and fractures in older adults are important and relevant outcomes to patients and clinicians because of their association with traumatic brain injury, institutionalization and death. ${ }^{16-18}$ Details on how we defined this outcome are listed in Appendix 1, Section 5 .

\section{Statistical analysis}

We compared the patient and hospital admission characteristics for hospital discharge episodes before and after implementation of the electronic medication reconciliation system using standardized differences. ${ }^{19} \mathrm{We}$ assessed the association between implementation and outcomes using segmented linear regression analysis of 19 intervals before, and 30 intervals after, implementation. This number of intervals was adequate for an interrupted time-series analysis. ${ }^{20}$ The model included regression coefficients to determine whether there was a significant trend (slopes before and after use of an electronic medication reconciliation system) or a significant interval change (an immediate change after system implementation).

We confirmed model assumptions of homoscedasticity, linearity and normality graphically. We confirmed the absence of autocorrelation using the Durbin-Watson statistic, and used the Cook D statistic to ensure there were no unusual or influential data points. ${ }^{21} \mathrm{We}$ used the $\chi^{2}$ test to assess dif- ferences in proportions. We conducted statistical analyses using SAS 9.4, and considered 2-sided $p$ values less than 0.05 statistically significant.

\section{Ethics approval}

This project was approved by the Western University Research Ethics Board (\#112138).

\section{Results}

We identified 15932 patients who had a total of 18405 hospital discharge episodes (Figure 1). Comorbidities were frequent in our patient population (Table 1); the patient characteristics of the hospital discharge episodes before and after implementation of the electronic medication reconciliation system were similar, aside from a lower proportion of ischemic heart disease after implementation, and a slightly lower number of previous specialist visits.

The hospital admission characteristics were also similar between the 2 time periods, aside from the length of stay, which was a median of 1 day shorter after implementation of the electronic medication reconciliaton system (Table 2). The top 3 most common diagnoses at admission (representing about $15 \%$ of admissions) were the same both before and after implementation, namely coronary artery disease, osteoarthritis and aortic valve stenosis.

A potentially inappropriate study medication was dispensed in the outpatient setting in 2641 (14.3\%) of 18405 hospital discharge episodes. After the implementation of the electronic medication reconciliation system, there was a sudden and significant decline in hospital discharges associated with such dispensing $(-7.00 \%, 95 \%$ confidence interval [CI] -9.50 to -4.50$)$ and a small but significant change in the slope time $(-0.40 \%, 95 \%$ CI -0.61 to -0.19$)$ per 2 -month interval (details in Table 3 and Figure 2). The outpatient medication prescriptions that declined most after implementation were benzodiazepines and gastric acid suppressants (Table 4).

There were 5240 hospital discharge episodes (4809 patients) in which patients were newly dispensed an antipsychotic or a benzodiazepine during their hospital stay (cohort details shown in Appendix 1, Section 6). After these hospital discharge episodes, $175(3.3 \%)$ presented to a hospital or emergency department with a fall or fracture within 90 days of hospital discharge. There was a significant drop in falls or fractures immediately after implementation of the electronic system $(-2.32 \%, 95 \%$ CI -4.30 to -0.34 ), and the change in slope was nonsignificant (Table 3 and Figure 3).

\section{Interpretation}

When patients move between care settings, there is a potential for unintentional medication errors, and discharge from hospital is a particularly risky transition. ${ }^{2} \mathrm{We}$ report on the effect of an enhanced electronic medication reconciliation system that was introduced through a commercial EMR upgrade in 3 regional hospitals. We found the introduction of the electronic system was associated 


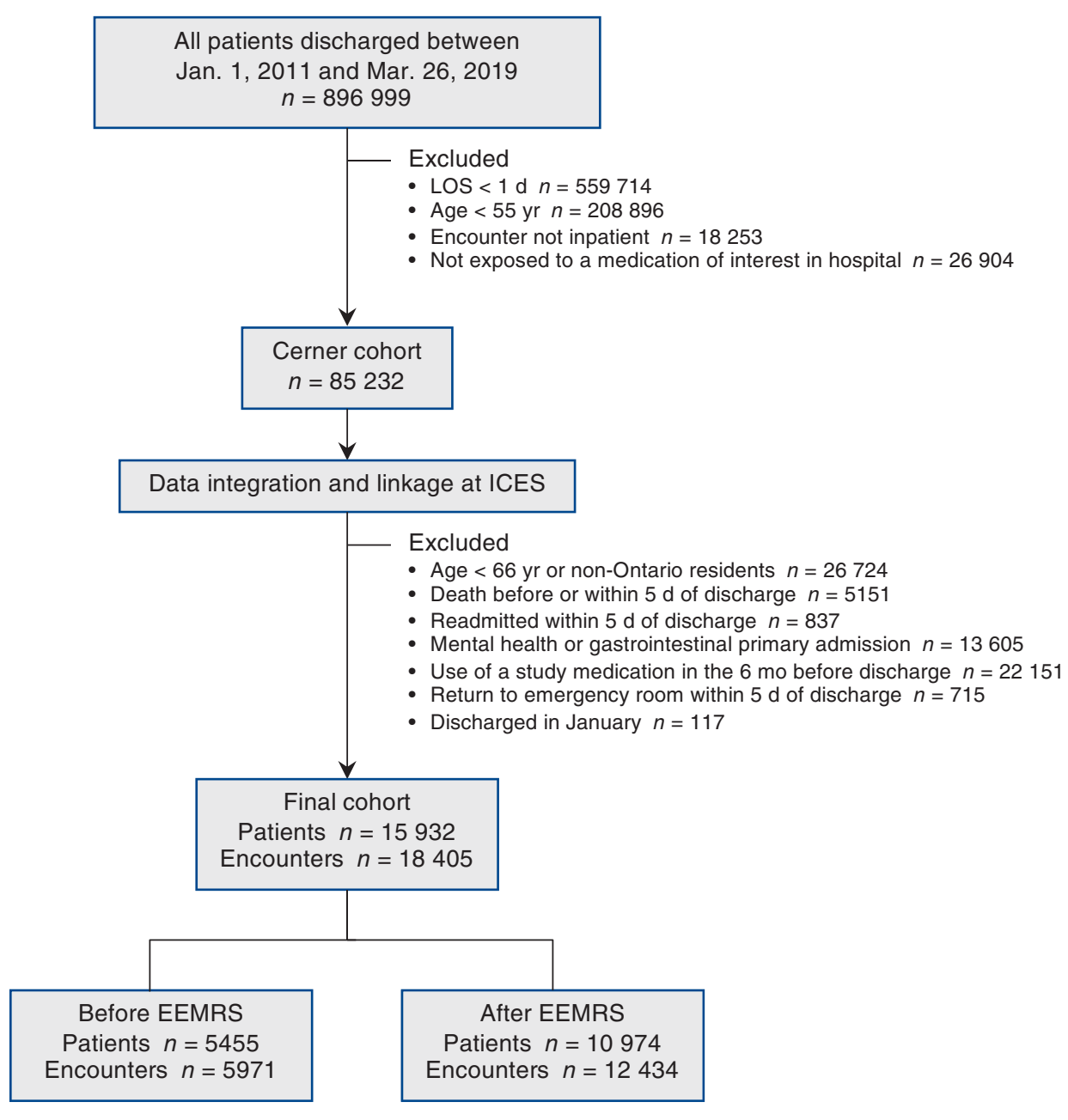

Figure 1: Study flow diagram. The pre-implementation period ("before EEMRS") includes 19 2-month intervals (Feb, 1, 2011, to Mar. 31, 2014), and the postimplementation period ("after EEMRS") includes 30 2-month intervals (Apr. 1, 2014, to Mar. 26, 2019). Note: EEMRS = electronic medication reconciliation systems, LOS = length of stay.

with an immediate, significant decrease in the proportion of older patients who filled prescriptions for potentially inappropriate, unsafe medications (i.e., benzodiazepines, antipsychotics and gastric acid suppressants) after hospital discharge. Importantly, in the subset of patients who were prescribed benzodiazepines or antipsychotics, there was a corresponding immediate drop in the proportion of patients who returned to hospital with a fall or fracture, which is a known adverse effect of both these medications in older adults. ${ }^{12,13}$

Although many interventions have been developed to improve medication reconciliation, most are multifaceted approaches that require pharmacist involvement, postdischarge follow-up or patient education. ${ }^{22}$ Despite substantial technological upgrades in the medication reconciliation process, only a few studies have evaluated commercially available electronic medication reconciliation systems, and limited evidence has shown that these updates lead to improvements in patient care. ${ }^{23,24}$ For example, the MARQUIS study was a multicentre, quality improvement study that was carried out at 5 hospitals in the United States. The implementation of 11 interventions designed to support medication reconciliation resulted in a small reduction in medication discrepancies, but there was no significant reduction in potentially harmful discrepancies. ${ }^{25}$ A cluster-randomized study from selected hospital units at McGill University Health Centre showed that an electronic tool that integrated community and hospital pharmacy records and introduced a medication reconciliation system led to a reduction in medication discrepancies, but did not reduce adverse drug events or future 


\begin{tabular}{|c|c|c|c|}
\hline \multirow[b]{2}{*}{ Variable } & \multicolumn{2}{|c|}{ No. $(\%)$ of patients* } & \multirow[b]{2}{*}{$\begin{array}{l}\text { Standardized } \\
\text { difference, \% }\end{array}$} \\
\hline & $\begin{array}{c}\text { Before } \\
\text { implementation } \dagger \\
n=5971\end{array}$ & $\begin{array}{c}\text { After } \\
\text { implementation } \neq \\
n=12434\end{array}$ & \\
\hline \multicolumn{4}{|l|}{ Demographics } \\
\hline Age, yr, median (IQR) & $74(69-80)$ & $74(69-80)$ & 5 \\
\hline Sex, male & $3350(56.1)$ & $6853(55.1)$ & 2 \\
\hline Lowest income quintile & $1052(17.6)$ & $2352(18.9)$ & 3 \\
\hline Highest income quintile & $1334(22.3)$ & $2544(20.5)$ & 5 \\
\hline Long-term care resident & $41(0.7)$ & $91(0.7)$ & 1 \\
\hline \multicolumn{4}{|l|}{ Comorbidities } \\
\hline $\begin{array}{l}\text { Charlson comorbidity score, median } \\
\text { (IQR) }\end{array}$ & $0(0-1)$ & $0(0-1)$ & 0 \\
\hline Chronic obstructive pulmonary disease & $438(7.3)$ & $886(7.1)$ & 1 \\
\hline Diabetes & $485(8.1)$ & $745(6.0)$ & 8 \\
\hline Hypertension & $766(12.8)$ & $1235(9.9)$ & 9 \\
\hline Ischemic heart disease & $1470(24.6)$ & $2452(19.7)$ & 11 \\
\hline Liver disease & $64(1.1)$ & $192(1.5)$ & 4 \\
\hline Inflammatory bowel disease & $707(11.8)$ & $1459(11.7)$ & 0 \\
\hline Renal disease & $394(6.6)$ & $923(7.4)$ & 3 \\
\hline Arthritis & $38(0.6)$ & $95(0.8)$ & 2 \\
\hline Stroke & $161(2.7)$ & $362(2.9)$ & 1 \\
\hline Cerebrovascular disease & $214(3.6)$ & $464(3.7)$ & 1 \\
\hline Dementia & $25(0.4)$ & $60(0.5)$ & 1 \\
\hline Congestive heart failure & 947 (15.9) & $2043(16.4)$ & 2 \\
\hline \multicolumn{4}{|l|}{ Previous health care utilization } \\
\hline $\begin{array}{l}\text { No. of outpatient internal medicine } \\
\text { specialist visits in previous year, median } \\
\text { (IQR) }\end{array}$ & $0(0-1)$ & $0(0-1)$ & 21 \\
\hline $\begin{array}{l}\text { No. of primary care visits in previous } \\
\text { year, median (IQR) }\end{array}$ & $3(1-8)$ & $3(1-8)$ & 0 \\
\hline \multicolumn{4}{|l|}{ Medication use } \\
\hline $\begin{array}{l}\text { No. of medications in previous year, } \\
\text { median (IQR) }\end{array}$ & $7(4-11)$ & $7(4-11)$ & 1 \\
\hline $\begin{array}{l}\text { Polypharmacy at admission ( } \geq 10 \\
\text { different daily prescription medications in } \\
\text { the last year) }\end{array}$ & $2075(34.8)$ & 4249 (34.2) & 1 \\
\hline $\begin{array}{l}\text { Note: IQR = interquartile range. } \\
\text { *Unless indicated otherwise. } \\
\text { †Before Mar. } 31,2014 . \\
\text { †After Apr. } 1,2014 .\end{array}$ & & & \\
\hline
\end{tabular}

hospital encounters. ${ }^{8}$ In contrast, our study focused on 3 specific medication classes that have the potential to cause harm, rather than all possible medications. Our results provide evidence of an added benefit from an electronic medication reconciliation system that, when shared with physicians and health administrators at other hospitals, may improve buy-in for adopting such a system.
Our study is timely and relevant, as many Canadian hospitals are deliberating whether to adopt an electronic medication reconciliation system. ${ }^{26}$ Future efforts should continue to evaluate the clinical benefit of EMR systems in Canada. Theoretical benefits associated with new systems and processes should continue to be evaluated to ensure they are usable and improve patient care. New EMR modules 


\begin{tabular}{|c|c|c|c|}
\hline \multirow[b]{2}{*}{ Variable } & \multicolumn{2}{|c|}{ No. $(\%)$ of patients* } & \multirow[b]{2}{*}{$\begin{array}{l}\text { Standardizec } \\
\text { difference, } \%\end{array}$} \\
\hline & $\begin{array}{c}\text { Before } \\
\text { implementation } \\
n=5971\end{array}$ & $\begin{array}{c}\text { After } \\
\text { implementation } \\
n=12434\end{array}$ & \\
\hline $\begin{array}{l}\text { Hospital length of stay, median } \\
\text { (IQR) }\end{array}$ & $7(4-12)$ & $6(3-10)$ & 21 \\
\hline \multicolumn{4}{|l|}{ Type of inpatient service } \\
\hline Medical & $1783(29.9)$ & $4098(33.0)$ & 7 \\
\hline Surgical & 3957 (66.3) & $7850(63.1)$ & 7 \\
\hline Other & $231(3.9)$ & $486(3.9)$ & 0 \\
\hline Transfer from ED to inpatient & $2403(40.2)$ & 4699 (37.8) & 5 \\
\hline ICU admission & $1727(28.9)$ & $3289(26.5)$ & 6 \\
\hline $\begin{array}{l}\text { Surgery or procedure } \\
\text { performed }\end{array}$ & 5247 (87.9) & $11254(90.5)$ & 8 \\
\hline Discharged to long-term care & $184(3.1)$ & $249(2.0)$ & 7 \\
\hline
\end{tabular}

\begin{tabular}{|c|c|c|c|}
\hline \multirow[b]{2}{*}{ Outcome } & \multicolumn{2}{|c|}{ Slope, \% (95\% Cl) } & \multirow{2}{*}{$\begin{array}{l}\text { Absolute change } \\
\text { immediately after } \\
\text { implementation, \% }(95 \% \mathrm{Cl})\end{array}$} \\
\hline & $\begin{array}{l}\text { Before implementation } \\
\text { (per 2-mo interval) }\end{array}$ & $\begin{array}{l}\text { After implementation } \\
\text { (per 2-mo interval) }\end{array}$ & \\
\hline Process & $0.42(0.20$ to 0.64$)$ & $-0.40(-0.61$ to -0.19$)$ & $-7.00(-9.50$ to -4.50$)$ \\
\hline Clinical & $0.06(-0.09$ to 0.21$)$ & $-0.02(-0.11$ to 0.17$)$ & $-2.32(-4.30$ to -0.34$)$ \\
\hline \multicolumn{4}{|c|}{$\begin{array}{l}\text { Note: } \mathrm{Cl}=\text { confidence interval. } \\
\text { "The primary process outcome was receipt of a medication of interest within } 5 \text { days of discharge. The primary clinical } \\
\text { outcome was a hospital visit for a fall or fracture within } 90 \text { days of hospital discharge among patients who received a } \\
\text { benzodiazepine or an antipsychotic in hospital. }\end{array}$} \\
\hline
\end{tabular}

that require physician completion should be selected judiciously, as these new processes are linked to changes in workflow and additional administrative tasks that can lead to burnout and frustration in the workplace. ${ }^{27}$

\section{Limitations}

We used routinely collected data to conduct our study; therefore, there is a possibility of misclassification of study variables. The continued use of study medications after hospital discharge was likely appropriate in some patient discharges in our study, and thus we used the term "potentially inappropriate medication use." We could look only at dispensed prescriptions; therefore, we may have underestimated the outcome if patients received prescriptions they did not fill. The use of segmented regression is an appropriate method for evaluating the longitudinal effect of an intervention; however, it is still a quasiexperimental approach that is susceptible to confounding. It is possible that other prescribing changes or hospital system changes may have been occurring during the same period and may have contributed to the effect we observed. The enhanced electronic medication reconciliation system likely had increased uptake with time, and thus we may have underestimated its effectiveness in the initial time periods after implementation. Finally, this study was carried out in older adults, and represents the impact of a transition from a hospital-specific, paper-based medication reconciliation process to a commercially implemented electronic system. These results may not be generalizable to other patient populations, or other implementation processes. 


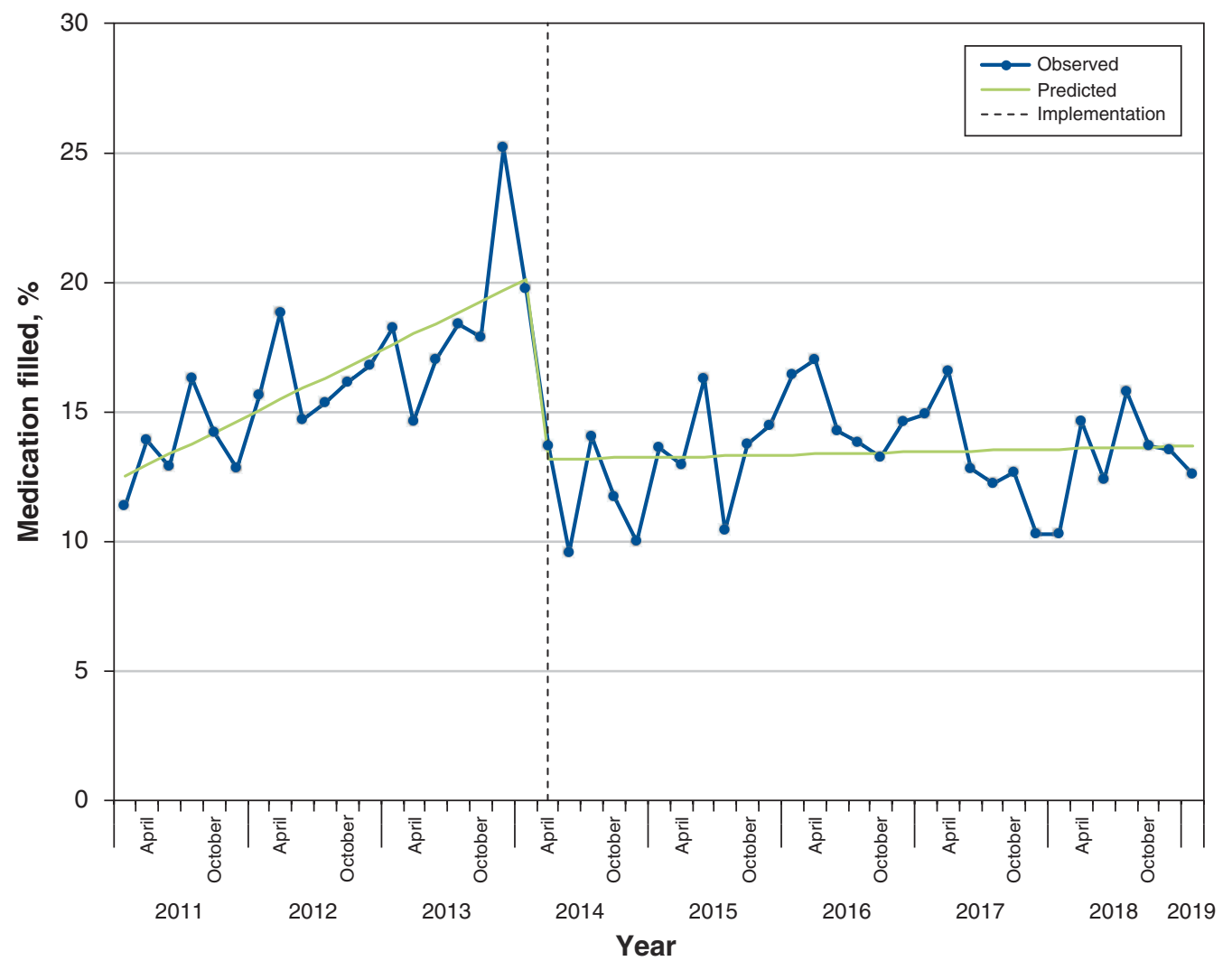

Figure 2: Proportion of hospital discharge episodes associated with a prescription filled for a benzodiazepine, antipsychotic or gastric acid suppressant in the outpatient setting, in 2-month intervals from Feb. 1, 2011, to Mar. 26, 2019. The dotted line represents the implementation date of the electronic medication reconciliation system.

\begin{tabular}{|c|c|c|c|c|c|}
\hline \multirow[b]{2}{*}{ Medication } & \multicolumn{2}{|c|}{$\begin{array}{c}\text { No. of hospitalization episodes with } \\
\text { medication }\end{array}$} & \multicolumn{2}{|c|}{$\begin{array}{c}\text { No. }(\%) \text { of discharge episodes with } \\
\text { medication }\end{array}$} & \multirow{2}{*}{$\begin{array}{c}\text { Absolute } \\
\text { difference, \% } \\
(95 \% \mathrm{Cl})\end{array}$} \\
\hline & $\begin{array}{c}\text { Before } \\
\text { implementation }\end{array}$ & $\begin{array}{c}\text { After } \\
\text { implementation }\end{array}$ & $\begin{array}{c}\text { Before } \\
\text { implementation }\end{array}$ & $\begin{array}{c}\text { After } \\
\text { implementation }\end{array}$ & \\
\hline All medications & 5971 & 12434 & $971(16.3)$ & $1670(13.4)$ & $-2.9(-3.9$ to -1.7$)$ \\
\hline Antipsychotics & 438 & 986 & $20(4.6)$ & $43(4.4)$ & $-0.2(-2.5$ to 2.1$)$ \\
\hline Benzodiazepines & 3047 & 6190 & $95(3.1)$ & $129(2.1)$ & $-1.0(-1.8$ to -0.3$)$ \\
\hline $\begin{array}{l}\text { Gastric acid } \\
\text { suppressants }\end{array}$ & 4438 & 8727 & 855 (19.3) & $1489(17.1)$ & $-2.2(-3.6$ to -0.8$)$ \\
\hline
\end{tabular}

\section{Conclusion}

The implementation of a commercially available, enhanced electronic medication reconciliation system in 3 Canadian hospitals was associated with a significant and immediate decrease in the proportion of patients who filled a potentially inappropriate prescription for benzodiazepines, antipsychotics or gastric acid suppressants when they transitioned back to the community. Among 


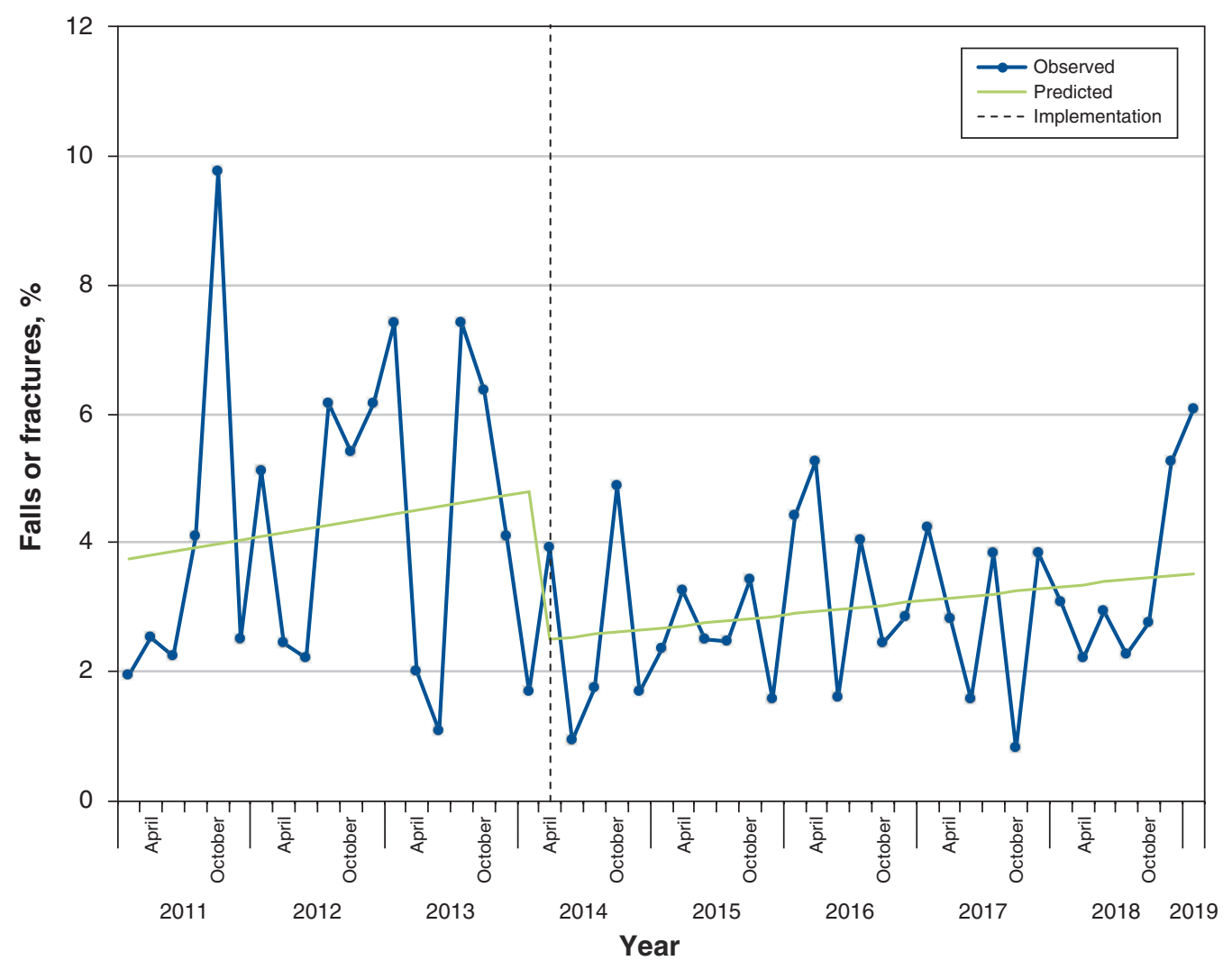

Figure 3: Proportion of hospital discharge episodes in the subgroup exposed to a benzodiazepine or antipsychotic that were associated with a fall or fracture within 90 days of hospital discharge, in 2-month intervals from Feb. 1, 2011 to Mar. 26, 2019. The dotted line represents the implementation date of the electronic medication reconciliation system.

people who were exposed to benzodiazepines or antipsychotics in hospital, use of the electronic system was associated with a significantly lower chance of patients returning to a hospital or emergency department from a fall or fracture after hospital discharge.

\section{References}

1. Kwan JL, Lo L, Sampson M, et al. Medication reconciliation during transitions of care as a patient safety strategy: a systematic review. Ann Intern Med 2013;158:397-403.

2. Alqenae FA, Steinke D, Keers RN. Prevalence and nature of medication errors and medication-related harm following discharge from hospital to community settings: a systematic review. Drug Saf 2020;43:517-37.

3. Mueller SK, Sponsler KC, Kripalani S, et al. Hospital-based medication reconciliation practices: a systematic review. Arch Intern Med 2012;172:1057-69.

4. Scales DC, Fischer HD, Li P, et al. Unintentional continuation of medications intended for acute illness after hospital discharge: a population-based cohort study. 7 Gen Intern Med 2016;31:196-202.

5. Health Quality Ontario. Medication reconciliation at discharge. Toronto: Queen's Printer for Ontario. Available: http://indicatorlibrary.hqontario.ca/ Indicator/Summary/Medication-reconciliation-discharge/EN (accessed 2020 Dec. 1).

6. About ITAC Health. Information Technology Association of Canada; 2014. Available: https://technationcanada.ca/wp-content/uploads/2020/10/Accelerating -Adoption-Health-Whitepaper-2018.pdf (accessed 2021 Nov. 11).
7. Chaudhry B, Wang J, Wu S, et al. Systematic review: impact of health information technology on quality, efficiency, and costs of medical care. Ann Intern Med 2006; 144:742-52.

8. Tamblyn R, Abrahamowicz M, Buckeridge DL, et al. Effect of an electronic medication reconciliation intervention on adverse drug events: a cluster randomized trial. FAMA Netw Open 2019;2:e1910756.

9. Lehnbom EC, Stewart MJ, Manias E, et al. Impact of medication reconciliation and review on clinical outcomes. Ann Pharmacother 2014;48:1298-312.

10. 2019 American Geriatrics Society Beers Criteria Update Expert Panel. American Geriatrics Society 2019 updated AGS Beers Criteria for potentially inappropriate medication use in older adults. 7 Am Geriatr Soc 2019; 67:674-94.

11. Benchimol EI, Smeeth L, Guttmann A, et al.; RECORD Working Committee. The REporting of studies Conducted using Observational Routinely-collected health data (RECORD) statement. PLoS Med 2015;12:e1001885.

12. Bell CM, Fischer HD, Gill SS, et al. Initiation of benzodiazepines in the elderly after hospitalization. 7 Gen Intern Med 2007;22:1024-9.

13. Masand PS. Side effects of antipsychotics in the elderly. 7 Clin Psychiatry 2000;61 (Suppl 8):43-9, discussion 50-1.

14. Logan IC, Sumukadas D, Witham MD. Gastric acid suppressants: Too much of a good thing? Age Ageing 2010;39:410-1.

15. Sheen E, Triadafilopoulos G. Adverse effects of long-term proton pump inhibitor therapy. Dig Dis Sci 2011;56:931-50.

16. Bliuc D, Nguyen ND, Milch VE, et al. Mortality risk associated with lowtrauma osteoporotic fracture and subsequent fracture in men and women. 7AMA 2009;301:513-21.

17. Thompson HJ, McCormick WC, Kagan SH. Traumatic brain injury in older adults: epidemiology, outcomes, and future implications. 7 Am Geriatr Soc 2006;54:1590-5. 
18. Tinetti ME, Kumar C. The patient who falls: "It's always a trade-off. $7 A M A$ 2010;303:258-66.

19. Austin PC. Using the standardized difference to compare the prevalence of a binary variable between two groups in observational research. Commun Stat Simul Comput 2009;38:1228-34.

20. Yaffee RA, McGee M. An introduction to time series analysis and forecasting: with applications of SAS® and SPSS®. Cambridge (MA): Academic Press; 2000.

21. Wagner AK, Soumerai SB, Zhang F, et al. Segmented regression analysis of interrupted time series studies in medication use research. 7 Clin Pharm Ther 2002;27:299-309.

22. Guisado-Gil AB, Mejías-Trueba M, Alfaro-Lara ER, et al. Impact of medication reconciliation on health outcomes: an overview of systematic reviews. Res Social Adm Pharm 2020;16:995-1002.

23. Marien S, Krug B, Spinewine A. Electronic tools to support medication reconciliation: a systematic review. 7 Am Med Inform Assoc 2017;24:227-40.

24. Mekonnen AB, Abebe TB, McLachlan AJ, et al. Impact of electronic medication reconciliation interventions on medication discrepancies at hospital transitions: a systematic review and meta-analysis. BMC Med Inform Decis Mak 2016;16:112.

25. Schnipper JL, Mixon A, Stein J, et al. Effects of a multifaceted medication reconciliation quality improvement intervention on patient safety: final results of the MARQUIS study. BM7 Qual Saf 2018;27:954-64.

26. Stage 6 and 7 facilities by location. Chicago: HIMSS. Available: https://www. himssanalytics.org/stage-6-7-achievement (accessed 2020 Dec. 1).

27. Gardner RL, Cooper E, Haskell J, et al. Physician stress and burnout: the impact of health information technology. 7 Am Med Inform Assoc 2019;26:106-14.

Affiliations: Departments of Surgery (Welk), and Epidemiology and Biostatistics (Welk, Killin, Anderson, Garg), Western University; ICES Western (Welk, Killin, Reid, Anderson, Shariff, Garg); Arthur Labatt Family School of Nursing (Shariff) Western University; Department of Medicine (Appleton, Garg), Western University; St. Joseph's Healthcare and London Health Sciences Centre (Kearns), London, Ont.

Contributors: All authors contributed to study design. Jennifer Reid and Lauren Killin were responsible for the data analysis. Blayne Welk and Lauren Killin were responsible for drafting the manuscript. All authors provided critical revisions, approved the final version and agree to be accountable for the results. Blayne Welk and Lauren Killin contributed equally to the role of first author.

Funding: The study was supported by a grant from the Academic Medical Organization of Southwestern Ontario Innovation Fund (\#INN16-011), and the Lawson Strategic Research Fund, in partnership with the Clinical Informatics division of London Health Sciences
Centre and St. Joseph's Hospital. Dr. Amit Garg was supported by the Dr. Adam Linton Chair in Kidney Health Analytics and a Clinician Investigator Award from the Canadian Institutes of Health Research.

Content licence: This is an Open Access article distributed in accordance with the terms of the Creative Commons Attribution (CC BY-NC-ND 4.0) licence, which permits use, distribution and reproduction in any medium, provided that the original publication is properly cited, the use is noncommercial (i.e., research or educational use), and no modifications or adaptations are made. See: https://creativecommons.org/licenses/ by-nc-nd/4.0/

Data sharing: The data set from this study is held securely in coded form at ICES. Although legal data sharing agreements between ICES and data providers (e.g., health care organizations and government) prohibit ICES from making the data set publicly available, access may be granted to those who meet prespecified criteria for confidential access, available at https://www.ices.on.ca/DAS. The full data set creation plan and underlying analytic code are available from the authors upon request, understanding that the computer programs may rely upon coding templates or macros that are unique to ICES and are therefore either inaccessible or may require modification.

Acknowledgements: The authors thank IQVIA Solutions Canada Inc. for use of their Drug Information Database. Cerner data were provided through the cooperation of the London regional hospitals.

Supplemental information: For reviewer comments and the original submission of this manuscript, please see www.cmajopen.ca/content/9/4/ E1105/suppl/DC1

Disclaimer: The study was carried out by ICES Western. ICES is funded by an annual grant from the Ontario Ministry of Health $(\mathrm{MOH})$. Core funding for ICES Western is provided by several partners, including the Academic Medical Organization of Southwestern Ontario, the Schulich School of Medicine and Dentistry, Western University and the Lawson Health Research Institute. Parts of this material are based on data or information compiled and provided by the Canadian Institute for Health Information. The opinions, results and conclusions are those of the authors and are independent from these organizations. No endorsement by these organizations is intended or should be inferred. 